\title{
Difference in Malocclusion Knowledge between Mothers in Urban and Rural Area: A Cross-sectional Study
}

\author{
Ervina Sofyanti1 ${ }^{1, *}$ Darmayanti Siregar ${ }^{2}$ Yane Indira Pasaribu ${ }^{3}$ Magie Vania Halim ${ }^{3}$ \\ ${ }^{1}$ Department of Orthodontics, Faculty of Dentistry, Universitas Sumatera Utara, Medan 20155, Indonesia \\ ${ }^{2}$ Department of Dental Public Health, Faculty of Dentistry, Universitas Sumatera Utara, Medan 20155, Indonesia \\ ${ }^{3}$ Dentistry Program, Faculty of Dentistry, Universitas Sumatera Utara, Medan 20155, Indonesia \\ *Corresponding author.Email: ervina.sofyanti@usu.ac.id
}

\begin{abstract}
Some studies have reported about adequate relationship between mothers' knowledge and children's oral health status. Malocclusion is one of the major health issues after dental caries and periodontal disease which can worsen the oral health-related quality of life. Promoting dental health among mothers is a way to improve oral health since dental services are limited during the pandemic of COVID-19. The aim of this study is to analyze the knowledge about malocclusion between mothers in urban and rural areas. This cross-sectional study targeted mothers who live in Medan Anggrung district area as the urban group representative and Telagah village as the rural representative. They were asked based on the knowledge of malocclusion questionnaires including about the causes of malocclusion, the knowledge and awareness about malocclusion, knowledge about risk factors, and prevention of malocclusion. The level of knowledge assessment is based on Arikunto's which was categorized as high, moderate, and low. The difference analysis between the two-groups was based on Pearson Chi-square at significance level $(p<0.05)$. The knowledge of malocclusion in the rural area was higher than those living in the urban area. There was a significant difference of malocclusion knowledge between mothers in the urban and rural $(\mathrm{p}=0.00)$. It seems that dental health promotion can improve mothers' knowledge about malocclusion which affects their children's oral health. However, a further study based on clinical examinations should be done to analysis mothers' behaviour in keeping their children's oral health.
\end{abstract}

Keywords: Malocclusion, Knowledge, Mother.

\section{INTRODUCTION}

Malocclusion is usually identified as irregular teeth due to deviation of teeth and/or jaws that can affect aesthetic, oral function, and stomatognathic system. Causes of malocclusion are multifactorial originated from the combination of general and local factors. Malocclusion itself is a common disease that is not a lifethreatening condition. However, it might affect social and psychological well-being if left untreated. This impact can occur due to the facial aesthetics involved in malocclusion and oral dysfunctions such as problems in speech and mastication, periodontal diseases, and trauma [1], [2]. There are some essential indicators in preventing the malocclusion such as parent education, oral hygiene maintenance, preventing the oral habits, and dental care since early deciduous teeth [3].
Previous studies have reported that children's oral health depends on mothers' knowledge in providing and maintaining their children's oral hygiene. Thus, good knowledge and a positive attitude toward oral health are very important in preventing various dental problems, such as caries, gingivitis, and malocclusion [4]-[6]. Parental assistance is required because mothers bring huge impacts on creating children's behaviour since children's motor skills have not developed. This is why mothers play a great role to understand and provide facilities to their children in maintaining their oral health. Nowadays, a dental education program for mothers is considered to improve children's oral health and lead to a better quality of life. Dental facilities in urban is better than rural and the mass media plays an important role in dental health promotion recently since limited dental services during the pandemic of COVID-19. 
On September 2020, the community service activities from Dental Faculty of Universitas Sumatera Utara provided counselling about dental and oral health in the Telagah village, followed by training for cadres who work in the Integrated Healthcare Center to improve the dental health promotion during integrated service post activities. One of dental and oral health problem is malocclusion that might have association with stunting [7]. In order to obtain information about malocclusion knowledge among mothers, this study aims to analyse the knowledge about malocclusion between mothers in the urban and rural areas.

\section{MATERIALS AND METHODS}

This is a cross-sectional study of mothers' knowledge about malocclusion between Medan Anggrung district area as the urban group representative and Telagah village as the rural representative. Criteria of respondents who were in this study included married women aged between 18 to 45 years and registered as Anggrung district and Telagah Village citizens. The ethics committee at the University of Sumatera Utara (USU) approved the study protocol (79/KEP/USU/2020). This study is part of the community service program from the University of North Sumatera during pandemic COVID19 that was conducted in May 2021. A structured selfadministered questionnaire about malocclusion knowledge including the causes, awareness, risk factors, and prevention of malocclusion, was developed from Pravara Institute of Medical Sciences \& Rural Dental College, Loni, India [8]. The questionnaires contained true, false, and don't know for measuring knowledge of respondents about the causes of malocclusion, knowledge and awareness about malocclusion, knowledge about risk factors, and prevention of malocclusion. The level of knowledge assessment is based on Arikunto's that was categorized as high, moderate, and low [9].

The validity and reliability of these modified questionnaires were carried out in 20 respondents consisting of 10 respondents from each group. The validity test of 22 closed-ended questions from 10 respondents in each group showed an r-value of 0.444 . The reliability tests for the four categories of research questionnaires included are: causes of malocclusion ( $\mathrm{p}=$ $0.638)$, the knowledge and awareness about malocclusion $(p=0.750)$, knowledge about risk factors $(p=0.708)$, and prevention of malocclusion $(p=0.780)$. Since the questionnaires were valid and reliable, the analysis of the difference in knowledge of malocclusion between rural and urban women was carried out with the Pearson Chisquare at a significance level $(\mathrm{p}<0.05)$.

\section{RESULTS}

There were 59 respondents from each urban and rural group who were willing to participate in this survey study. The description of malocclusion Knowledge

Table 1. Difference in Malocclusion Knowledge between Mothers in Urban and Rural Area

\begin{tabular}{|c|c|c|c|c|}
\hline \multirow{2}{*}{ Domicile } & \multicolumn{3}{|c|}{ Knowledge Level } & \multirow{2}{*}{ P } \\
\cline { 2 - 4 } & High & Moderate & Low & \\
\hline \multirow{2}{*}{ Urban } & 22 & 16 & 21 & \\
\cline { 2 - 4 } & $37.3 \%$ & $27.1 \%$ & $35.6 \%$ & \multirow{2}{*}{$0.00^{*}$} \\
\hline \multirow{2}{*}{ Rural } & 50 & 7 & 2 & \\
\cline { 2 - 4 } & $11.9 \%$ & $11.9 \%$ & $3.4 \%$ & \\
\hline
\end{tabular}

between Mothers in Urban (Anggrung District, Medan Polonia) and Rural (Telagah Village) area was shown in table 1 . The knowledge of malocclusion in the rural area was higher than those who live in the urban area. There was a significant difference $(\mathrm{p}=0.00)$ of malocclusion knowledge between mothers in the urban and rural (Table $1)$.

$$
\text { *) } p<0.05 \text { : Significant difference }
$$

\section{DISCUSSION}

Parents play a pivotal role in affecting the character of children as they grow towards adulthood. The COVID19 period lockdown presents the opportunity for parents to be engaged in the lives of their children, including oral health education. More reassuring information about dental infection control measures should be delivered to this population and more efforts directed toward encouraging mothers to resume routine dental care to prevent disease progression [4], [10]. Malocclusion is not a life-threatening condition; however, it can affect a person's well-being if left untreated. The etiology of malocclusion is multifactorial and well discussed for any countries [1], [11]. This preliminary study was beneficial as basic in understanding the importance of knowledge and behaviour gained from maternal education towards oral health. A well-developed program is required to improve knowledge and behaviour in maintaining good oral health since pregnancy [12].

Mother's role in preventing malocclusion can be undertaken by controlling and guiding the functional and environmental factors that can regulate the craniofacial growth and development since pregnancy and encourage children to be aware of their oral health since an early age [3], [5]. Parental attention to nutritional status and bad habits, such as mouth breathing are associated with the development of crowding malocclusion in permanent dentition [13]. Our study believes that mothers education is part of active orthodontic treatment as one of the preventive strategies to provide normal function and structures of dentocraniofacial growth which could 
reduce the prevalence of malocclusion. Understanding certain oral bad habits that can direct or indirect affect a child's malocclusion is fundamental knowledge for mothers in preventive malocclusion aspect.

This study showed that the level of malocclusion knowledge was higher in the rural than the urban mother group and there was a significant difference of mother's knowledge (Table 1). Although dental facilities in urban area is better than rural, it is not a guarantee that knowledge level in urban is better than in rural. It is probably due to urban mothers' ignorant characteristic probably influenced the assessment of the level of knowledge about malocclusion in general. The urban mothers were considered to have enough knowledge and did not receive counselling because dental care facilities are already affordable in urban areas. Higher level of malocclusion knowledge for rural mother also because an activity was conducted the previous year which was the socialization of dental and oral health to mothers of productive age in Telagah village.

This observation is expected to initiate and increase awareness of the importance of dental health promotion in malocclusion even though the researcher's expert assessment still considers that the problem of domicile is related to limited information. This pandemic of COVID19 limited mother in the urban area to bring their children for dental check-up. Lastly, a further longitudinal study will be required to assess the suitability of the knowledge level and behaviour of the society.

\section{CONCLUSION}

The knowledge of malocclusion in the rural area was higher than those living in the urban area. There was a significant difference in malocclusion knowledge between mothers in the urban and rural $(p=0.00)$. The education meant to increase maternal knowledge about malocclusion is an effective malocclusion preventive effort, especially early orthodontic preventive.

\section{AUTHORS' CONTRIBUTIONS}

ES directed the project and wrote the manuscript. DS analysed the data. YIP and MVH collected data. All authors critically reviewed and approved the final draft and also responsible for the content of the manuscript.

\section{ACKNOWLEDGMENTS}

We are thankful for the continuous support of "desa binaan" program from Universitas Sumatera Utara Community Service Institutions (No. 258/UN5.2.3.2.1/PPM/2020 and

\section{REFERENCES}

[1] Z. A. Al Hammad, M. N. Aldosari, and W. T. Aldebasi, "Malocclusion in Saudi Arabia: A scoping review," Int. J. Appl. Dent. Sci., vol. 5, no. 1, pp. 37-41, 2019, [Online]. Available: https://www.oraljournal.com/pdf/2019/vol5issue1/ PartA/5-1-19-918.pdf.

[2] K. A. Kolawole and M. O. Folayan, "Association between malocclusion, caries and oral hygiene in children 6 to 12 years old resident in suburban Nigeria," BMC Oral Health, vol. 19, no. 1, p. 262, 2019, doi: 10.1186/s12903-019-0959-2.

[3] V. Vsn, "The prevention of malocclusions," Open Access J. Dent. Sci., vol. 2, no. 3, p. 000140, 2017, doi: $10.23880 /$ oajds-16000140.

[4] S. S. Alzaidi, I. A. Alanazi, and O. M. Abo Nawas, "Childhood oral health: maternal knowledge and practice in Tabuk, Saudi Arabia," Egypt. J. Hosp. Med., vol. 70, no. 9, pp. 1544-1551, 2018, doi: $10.12816 / 0044681$.

[5] M. Abdat and I. Ramayana, "Relationship between mother's knowledge and behaviour with oral health status of early childhood," Padjadjaran J. Dent., vol. 32, no. 3, pp. 166-73, 2020, doi: 10.24198/pjd.vol32no2.24734.

[6] O. O. Olatosi, A. Oyapero, N. K. Onyejaka, and G. O. Boyede, "Maternal knowledge, dental service utilization and self-reported oral hygiene practices in relation to oral health of preschool children in Lagos, Nigeria," PAMJ - One Heal., vol. 2, no. 10, p. $10.11604,2020$, doi: 10.11604/pamjoh.2020.2.10.22850.

[7] E. Sofyanti, "Kesehatan Gigi dan Mulut Salah Satu Kunci Pencegahan Stunting," Analisa Daily, 2020. https://analisadaily.com/berita/baca/2020/09/15/10 09536/kesehatan-gigi-dan-mulut-salah-satu-kuncipencegahan-stunting/ (accessed Apr. 30, 2021).

[8] U. Soni, M. Baheti, S. Dash, N. Toshniwal, and R. Baldawa, "Knowledge and awareness of malocclusion among rural population in India," Asian Pac. J. Heal. Sci., vol. 1, no. 4, pp. 329-34, 2014.

[9] Arikunto, Research Procedure: A Practical Approach. Jakarta: PT. Rineka Cipta, 2006.

[10] D. Farsi and N. Farsi, "Mothers' knowledge, attitudes, and fears about dental visits during the COVID-19 pandemic: a cross-sectional study," J Int Soc Prev. Communit Dent, vol. 11, pp. 83-91, 2021, doi: 10.4103/jispcd.JISPCD_395_20. 
[11] R. M. Sharaf and H. S. Jaha, "Etiology and treatment of malocclusion: Overview," Int. J. Sci. Eng. Res., vol. 8, no. 12, pp. 101-14, 2017.

[12] A. I. Soegyanto, R. N. Larasati, Y. S. Wimardhani, and B. Özen, "Mother's knowledge and behaviour towards oral health during pregnancy," Pesqui. Bras. Odontopediatria Clin. Integr., vol. 20, p. e5647, 2020, doi: 10.1590/pboci.2020.113.

[13] E. B. A. F. Thomaz, M. C. T. Cangussu, A. A. M. da Silva, and A. M. O. Assis, "Is malnutrition associated with crowding in permanent dentition?," Int. J. Environ. Res. Public Health, vol. 8, pp. 353144, 2010, doi: 10.3390/ijerph7093531. 